\title{
A second DNA binding site on RFC facilitates clamp loading at gapped or nicked DNA
}

\author{
Xingchen Liu $^{a^{*}}$, Christl Gaubitz ${ }^{a^{\star}}$, Joshua Pajak ${ }^{a}$, Brian A Kelch ${ }^{a}$ \\ ${ }^{a}$ Department of Biochemistry and Molecular Biotechnology, University of Massachusetts Chan Medical School, \\ Worcester MA \\ I Correspondence to BAK: brian.kelch@umassmed.edu, address: 364 Plantation St., Worcester MA 01605, phone: \\ 508-856-8322; and to CG: cgaubitz@sund.ku.dk, address: Blegdamsvej 3B, Copenhagen DK-2200, Denmark, \\ phone: +45 35-333-500 \\ * These authors contributed equally.
}

\section{SUMMARY}

Clamp loaders place circular sliding clamp proteins onto DNA so that clamp-binding partner proteins can synthesize, scan, and repair the genome. DNA with nicks or small single-stranded gaps are common clamploading targets in DNA repair, yet these substrates would be sterically blocked given the known mechanism for binding of primer-template DNA. Here, we report the discovery of a second DNA binding site in the yeast clamp loader Replication Factor C (RFC) that aids in binding to nicked or gapped DNA. This DNA binding site is on the external surface and is only accessible in the open conformation of RFC. Initial DNA binding at this site thus provides access to the primary DNA binding site in the central chamber. Furthermore, we identify that this site can partially unwind DNA to create an extended single-stranded gap for DNA binding in RFC's central chamber and subsequent ATPase activation. Finally, we show that deletion of the BRCT domain, a major component of the external DNA binding site, results in defective yeast growth in the presence of DNA damage where nicked or gapped DNA intermediates occur. We propose that RFC's external DNA binding site acts to enhance DNA binding and clamp loading, particularly at DNA architectures typically found in DNA repair.

Keywords: sliding clamp, DNA replication \& repair, AAA+, ATPase, clamp loader

\section{INTRODUCTION}

Sliding clamps are ring-shaped proteins that surround DNA to tether DNA polymerases and other factors onto DNA. The sliding clamp of eukaryotes, Proliferating Cell Nuclear Antigen (PCNA), can bind to scores of different partners, and facilitates numerous pathways such as DNA replication, DNA repair, cell cycle control, and chromatin structure (Choe and Moldovan, 2017; Moldovan et al., 2007). Thus, PCNA is a highly adaptable protein because it can interact with a diverse array of protein partners and DNA substrates.

Because sliding clamps are closed in solution they must be loaded onto DNA by clamp loader ATPase complexes. Clamp loaders, like sliding clamps, are conserved throughout all life and are necessary for proper replication and regulation of the genome. Clamp loaders are members of the ATPases Associated with various cellular Activities $(A A A+)$ family of ATPases and are related to many other important macromolecular machines that regulate DNA replication, such as DNA replication initiators, helicases and helicase loaders (Erzberger and Berger, 2006). Unlike typical $\mathrm{AAA}+$ machines that function as hexamers, clamp loaders are all pentameric ATPases. Each subunit is termed $A$ through $E$ and consists of a AAA+ module connected to a C-terminal collar domain that oligomerizes the complex.
Because clamp loaders function in numerous pathways, they can utilize diverse nucleic acid substrates. The classical DNA substrate that clamp loaders use for DNA replication is primertemplate DNA (p/t-DNA), a duplex region with a 5' single-strand DNA (ssDNA) overhang and a recessed 3' end (Ason et al., 2003; Tsurimoto and Stillman, 1991). By loading a clamp onto $p / t-D N A$, clamp loaders position the sliding clamp to be subsequently utilized by a DNA polymerase to extend the primer strand 3' end (Naktinis et al., 1996). Structures of p/t-DNA-bound clamp loaders from archaea, bacteria, viruses and eukaryotes have revealed that the mechanism of $\mathrm{p} / \mathrm{t}-\mathrm{DNA}$ recognition is broadly conserved (Gaubitz et al., 2021; Kelch et al., 2011; Miyata et al., 2005; Simonetta et al., 2009). The duplex region of $\mathrm{p} / \mathrm{t}-\mathrm{DNA}$ is bound within the central chamber of the clamp loader with the 3' recessed end capped by the collar region. We recently reported that the eukaryotic clamp loaders have a "separation pin" that can melt the 3' base pair of the primer strand (Gaubitz et al., 2021). The ssDNA overhang of the template strand exits the central chamber through a gap in between the $A$ and $A^{\prime}$ ' domains that is termed the "A-gate". The A-gate plays a pivotal role in clamp loader function because it allows entry and egress of DNA from the clamp loader central chamber. We recently showed that the opening of the A-gate requires a massive conformational change from a closed, auto-inhibited state into an open, active conformation (Gaubitz et al., 2020, 2021). Moreover, the A-gate 
A
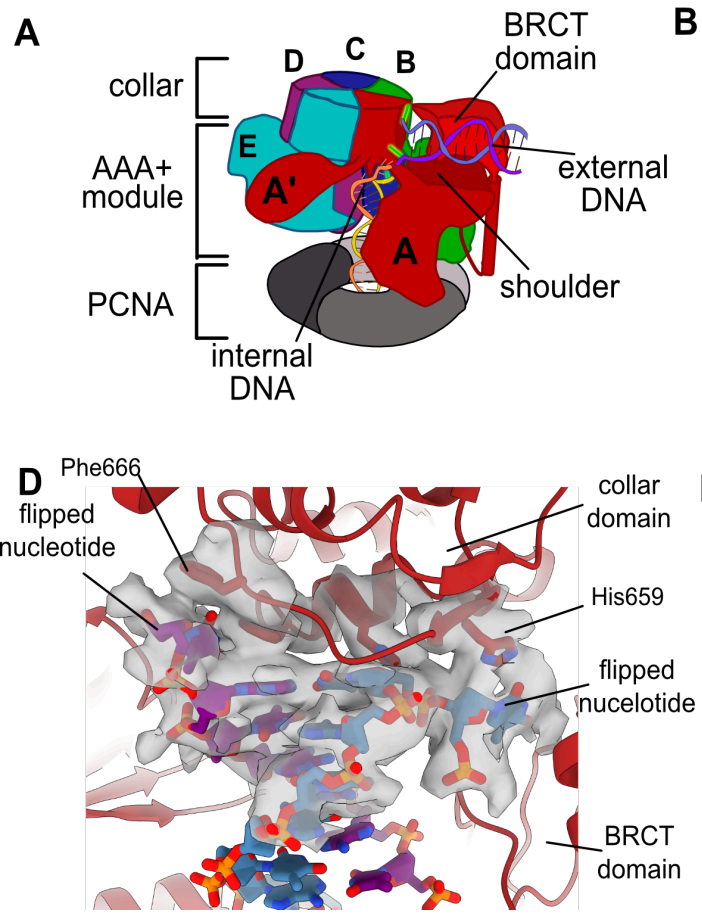

B

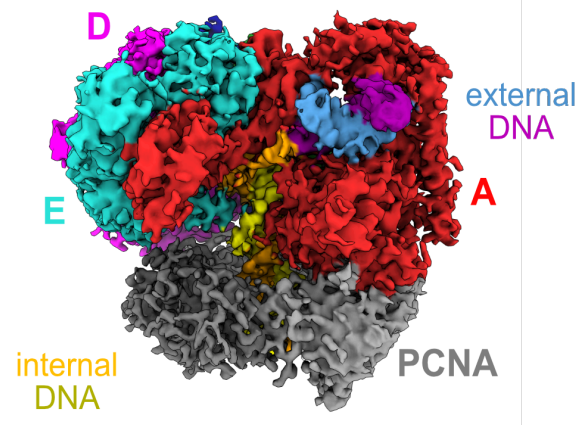

E

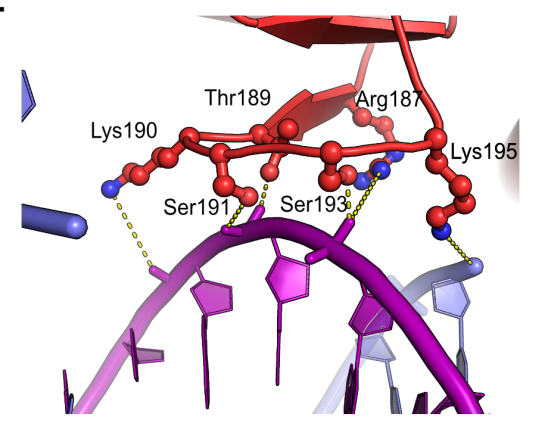

C

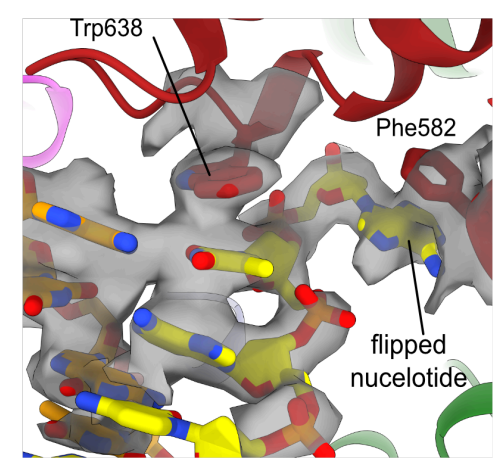

$\mathbf{F}$

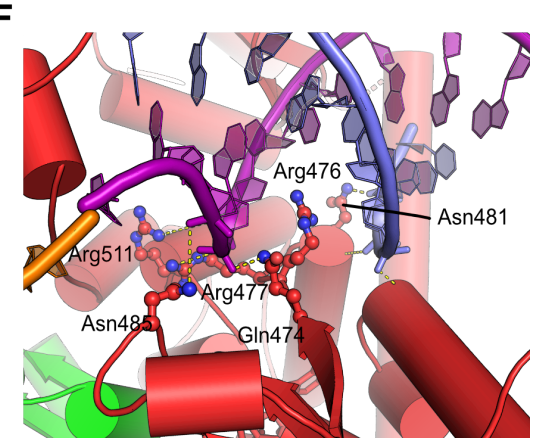

Figure 1: Structure of RFC:PCNA bound to two p/t-DNA molecules. (A) Schematic of the complex of RFC:PCNA bound to two p/t-DNAs. Melted base pairs are shown in glowing green sticks. (B) Cryo-EM reconstruction of the complex of RFC:PCNA bound to two $p / t-D N A s$. The strands of the external DNA are shown in slate and purple coloring. (C) The 3' nucleotide of the primer strand is melted at the internal separation pin. (D) The external DNA binding site also melts DNA. The two melted bases stack against Phe666 and His659. (E) The BRCT domain grips duplex DNA at the external DNA binding site. (F) The "shoulder" region of the AAA+ module grips duplex DNA, with several residues (Gln474 and Arg476) inserting into the minor groove, presumably setting the register of DNA.

provides specificity for a ssDNA region because the gap at the top of the central chamber is too kinked and narrow for dsDNA (Kelch et al. 2011; Gaubitz et al. 2021).

However, clamp loaders also utilize many DNA architectures other than $\mathrm{p} / \mathrm{t}-\mathrm{DNA}$, including small ssDNA gaps and even nicked DNA with no ssDNA (Matsumoto, 2001; Uhlmann et al., 1997). These substrates are more commonly seen in DNA repair pathways such as long patch Base Excision Repair (Ip-BER) (Matsumoto, 2001). Our recent structures of the yeast clamp loader RFC bound to $\mathrm{p} / \mathrm{t}$-DNA revealed that a "separation pin" in RFC melts the 3' end of primer. Although the function of this activity remains obscure, we hypothesize that the separation may be involved in binding different DNA architectures (Gaubitz et al., 2021). Moreover, non-classical clamp loaders called RFC-Like Complexes (RLCs), such as Rad24-RLC and Elg1-RLC utilize DNA structures with recessed 5' ends or fully dsDNA, respectively (Kubota et al., 2015; Majka and Burgers, 2004; Majka et al., 2006). Recent structures of Rad24-RLC show that the 5' recessed DNA is surprisingly accommodated on a second DNA binding site on the "shoulder" of Rad24 (Castaneda et al. 2021; Zheng et al. 2021). However, the structures of RFC and Rad24-RLC do not indicate how gapped or nicked DNA can bind to RFC. Moreover, it is not known how clamp loaders evolved different DNA binding specificity.

Here we describe a series of structures that reveal that RFC has a second binding site for DNA on the external surface of RFC. This external DNA binding site is composite, consisting of three domains of the A subunit: the (BRCA1 C-Terminus) BRCT, AAA+, and collar domains. Furthermore, we observe that this site is used to bind gapped or nicked DNA. CryoEM structures of RFC:PCNA bound to these DNA architectures reveal that the external DNA binding site is positioned to interact with the 5 ' duplex region of gapped or nicked DNA. To bind nicked DNA, the clamp loader must melt DNA at both the interior and the exterior DNA binding sites, indicating that RFC has two separation pins. Finally, we show that yeast specifically lacking the BRCT region of the external binding site exhibit a phenotype consistent with disrupted BER. Our results reveal a region of RFC used for binding DNA architectures commonly appear during DNA repair, and we link the evolution of altered DNA binding in Rad24-RLC to the classical clamp loader RFC.

\section{RESULTS}

\section{Structure of RFC:PCNA:p/tDNA reveals a second DNA binding site}

We previously described a series of structures of yeast RFC bound to PCNA, ATPyS, and p/t- DNA (Gaubitz et al., 2021). Here we describe a class at $3.4-\AA$ overall resolution from one of these datasets that contains a second DNA bound at a previously undescribed site (Figure 1A\&B; Supplemental Figure 1.1). The primary $\mathrm{p} / \mathrm{t}-\mathrm{DNA}$ binding site is filled normally, with the nucleotide at the 3' end of the primer flipped by the previously described internal separation pin (Gaubitz et al. 2021) (Figure 1C; Supplemental Figure 1.2). A second p/t-DNA molecule fortuitously binds to RFC on the outside of the complex (Figure 
bioRxiv preprint doi: https://doi.org/10.1101/2022.01.31.478526; this version posted January 31, 2022. The copyright holder for this preprint (which was not certified by peer review) is the author/funder, who has granted bioRxiv a license to display the preprint in perpetuity. It is made available under aCC-BY-NC-ND 4.0 International license.

A

RFC:PCNA bound to two $p / t-D N A s$

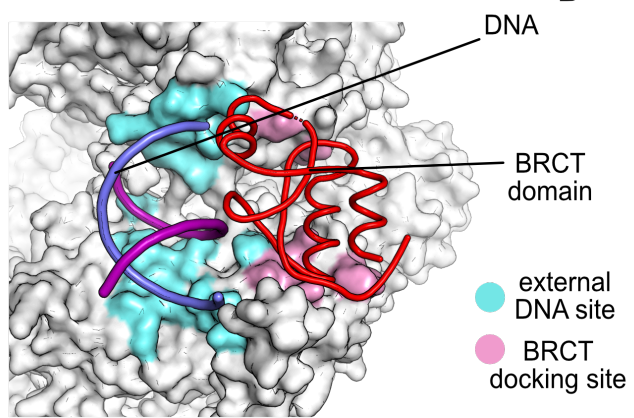

B

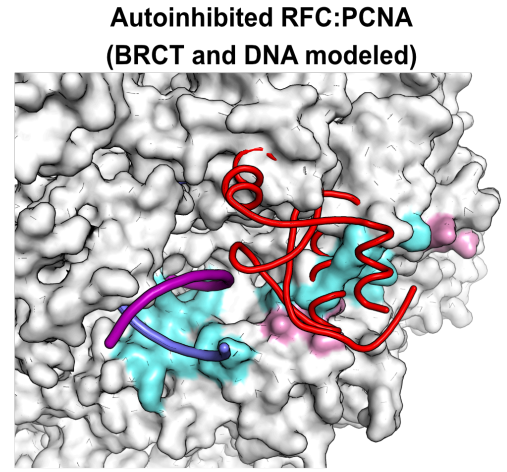

D



C

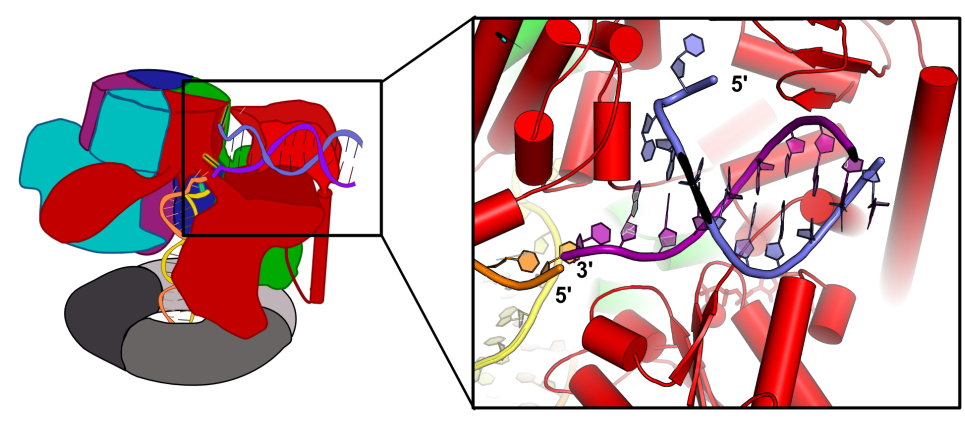

E

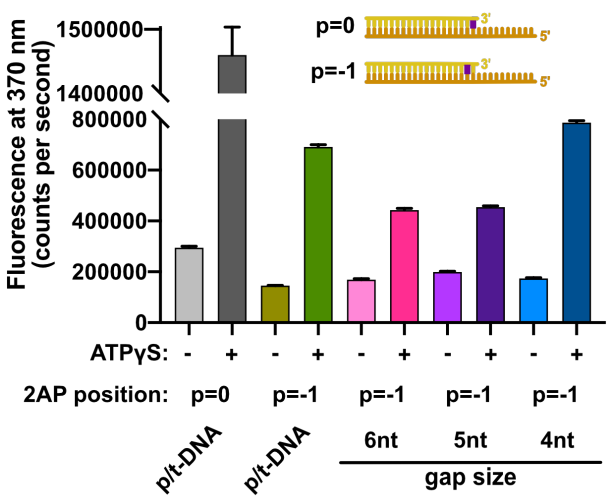

Figure 2: Characterization of RFC utilization of gapped DNA. (A\&B) The external DNA binding site is incompatible with autoinhibited forms of RFC. (A) The structure of RFC:PCNA bound to two $p / t-D N A s$, highlighting the external DNA binding site. The residues that interact with DNA and the BRCT domain are shown in light blue and pink, respectively. (B) The external DNA binding site is disabled in the autoinhibited form of RFC. The BRCA domain and DNA duplex are in the same position relative to the AAA+ fold show in panel A, with identical residues highlighted in light blue and pink, showing that the binding site is disrupted. Moreover, the collar and $A^{\prime}$ regions would sterically clash with the DNA and the BRCT domain. (C) Because $5^{\prime}$ end of the template strand of the internal DNA is positioned near the $3^{\prime}$ end of a strand in the external site, we hypothesized that the two DNA sites could be connected with a short ssDNA gap of approximately six nucelotides. (D) ATPase activity of the RFC:PCNA complex in the presence of gapped DNA. Steady-state ATPase rates of RFC:PCNA in the presence of $p / t-D N A$ or DNA constructs with various-sized ssDNA gaps. Decreasing gaps result in decreasing ATPase rates until four nucleotides of ssDNA, where ATPase rates increase. The trend is smooth and continuous, except for 6-nucleotide SsDNA, which is the size predicted to ideally span the distance between the internal and external sites. (E) 2-aminopurine (2AP) fluorescence measuring base-flipping in gapped DNA constructs. 2AP at the $p=-1$ position informs whether base-flipping occurs at $p=0$ and/or $p=-1$ position on the primer strand. $0.5 \mu \mathrm{M}$ RFC and $2 \mu \mathrm{M}$ PCNA were incubated with 2AP-containing DNA and fluorescence at $370 \mathrm{~nm}$ was recorded. We observe ATP-dependent fluorescence changes, particularly in the 4-nucleotide gapped DNA.

1A\&B). The second DNA binding site is just outside the exit channel for the single-stranded template overhang at the A-gate. The second DNA binding site is comprised entirely by the A subunit (Rfc1) at the "shoulder region", which is at the top of AAA+ module and next to the collar domain. We observe nine base pairs of duplex DNA, and a melted base pair in between the collar and BRCT domains (Figure 1B\&D). From the density alone it is difficult to assign the orientation of the bound DNA at the external site (i.e., which end of the construct is melted). While we cannot assign the exact sequence of the externally bound DNA, we can unambiguously assign the polarity of the strands using the major and minor grooves of DNA. Nevertheless, we establish that there are two DNA binding sites: one internal site that has been recognized since the first RFC structure (Bowman et al., 2004), and one external site that we describe here.

The BRCT domain in the N-terminal region of Rfc1 contributes to binding duplex DNA. The BRCT was not visible in any previous structures of RFC (Bowman et al., 2004; Gaubitz et al., 2020, 2021). The BRCT domain docks on the shoulder of Rfc1 where the collar and AAA+ module meet (Figure 1A\&B), and is connected to the $A A A+$ module through a long bridging helix. Although BRCT domains are primarily known for acting as protein-protein interaction modules (Leung and Glover, 2011), the Rfc1 BRCT domain binds DNA using a surface that has been shown to bind nucleic acids (Kobayashi et al., 2006, 2010). A series of positively charged and polar residues grip the phosphate backbone of both strands of the DNA duplex (Figure 1E). Because there are no interactions with individual bases, the binding mode is consistent with a lack of sequence specificity.

The second DNA binding site has major contributions from the shoulder and collar regions of Rfc1. In this sense, the external DNA binding site is a composite site consisting of interactions from three separate domains. The shoulder of the AAA+ domain exhibits a series of conserved polar and basic residues that grip the duplex, particularly Asn459, Gln474, Arg476, Arg477, Asn481, and Gln508 (Figure 1F; Supplemental Figure 1.3). In particular, Gln474 and Arg476 situate into the minor groove of the duplex, potentially setting the register of the bound DNA. Additionally, one of the strands is placed in between two helix dipoles that have their positive ( $\mathrm{N}$-terminal) ends pointed at the backbone of DNA. 
A

RFC:PCNA bound to 6-gap DNA

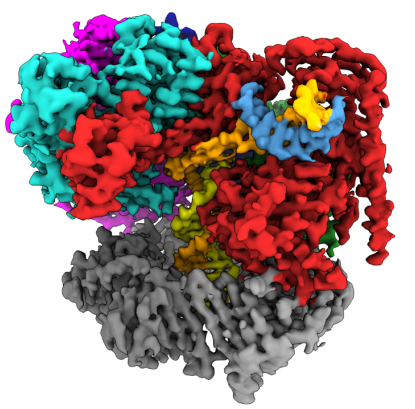

D

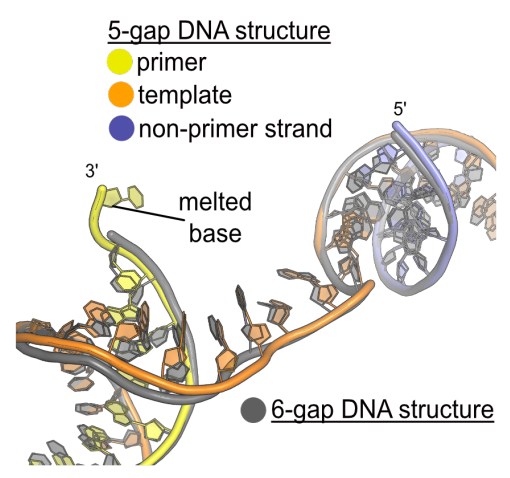

RFC:PCNA bound to 5-gap DNA

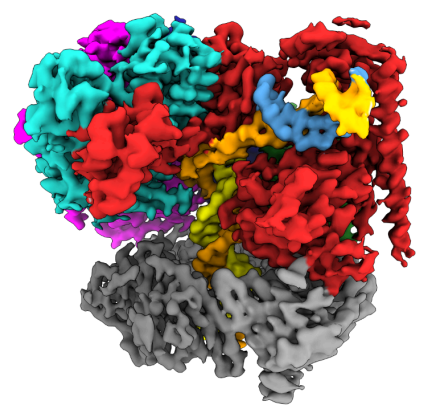

E

RFC:PCNA bound to 6-gap DNA
C

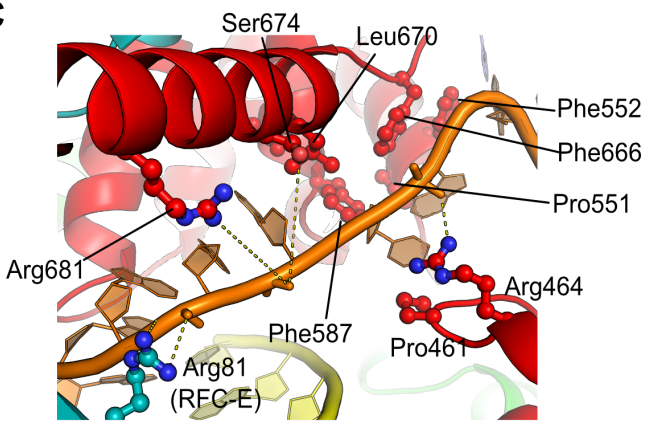

$\mathbf{F}$

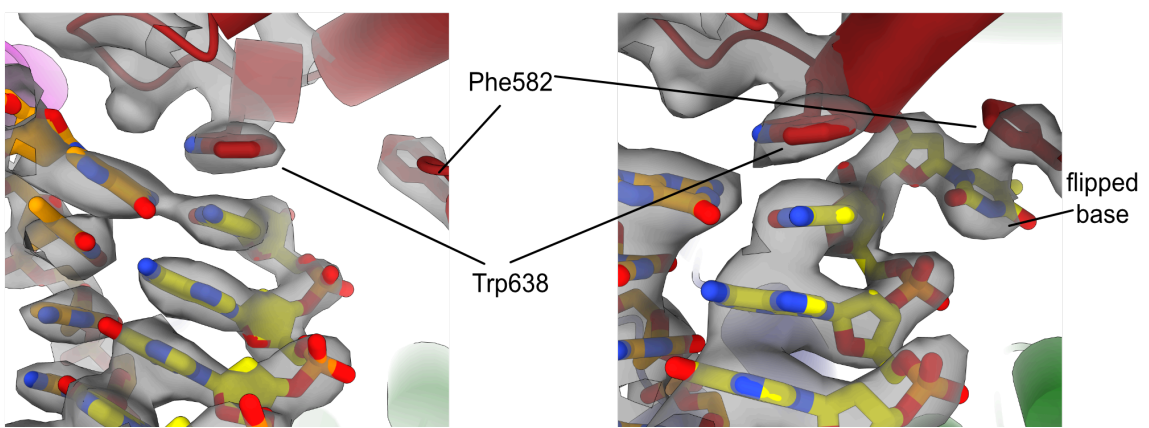

Figure 3: Structures of RFC:PCNA bound to gapped DNA. (A\&B) Cryo-EM reconstruction of the complex of RFC:PCNA bound to DNA with a ssDNA gap of six or five nucleotides (6-gap or 5-gap structures). (C) The single strand gap is specifically bound by residues comprising AAA+, collar and A' domains of the A subunit, as well as contacts from the E subunit. (D) DNA conformations in the 5-gap (yellow, orange and slate) and the 6-gap (gray) structures. The conformations of the DNA are nearly identical except the 5-gap DNA has melted a single base pair at the internal separation pin so that the ssDNA linker remains six nucleotides in length. (E) The 6-gap DNA binds with no melting at the internal separation pin. (F) The internal separation pin melts a single base pair at the internal separation pin.

This external DNA binding site is only accessible once RFC undergoes the crab-claw opening motion. In the Auto-inhbited conformation, this region is blocked by the A' domain and the collar domain of the E subunit, which would sterically block six of the nine base pairs of duplex DNA that we observe (Figure 2A\&B). Moreover, the site where the BRCT domain docks onto the shoulder of the AAA+ module of the RFC-A subunit is blocked by the collar domains of the $A$ and $E$ subunits. These sites only become accessible after the fold-switching event in the $A$ subunit that underlies the crab-claw motion for RFC opening (Gaubitz et al., 2021). Therefore, the second DNA binding site and docking of the BRCT domain are coupled to the binding and opening of PCNA.

While the BRCT and AAA+ shoulder regions grip the DNA backbone, the collar domain has several residues that are dedicated to melting and stabilizing the end of DNA (Figure 1D). Upon melting, one strand is directed towards a channel between the collar and BRCT domain, while the other strand is directed towards the A-gate. Several residues stabilize the melted bases: Phe552, His556, and lle664 stack against the duplex DNA and replace the melted bases, and His659 stacks against the melted base directed towards the BRCT domain. Thus, Rfc1 has two separation pins, one in the central chamber and a newly discovered one on the external DNA binding site. This external separation pin is remarkably similar to that used by Rad24-RLC when it binds DNA with a recessed 5' end (Castaneda et al., 2021; Zheng et al., 2021) (see discussion for more details).
To test the hypothesis that this external site can bind and melt 5 ' recessed ends, we used 2-aminopurine (2AP) fluorescence studies to report on base-flipping. 2AP is an adenine analog whose fluorescence is quenched when it is base-paired (Frey et al., 1995; Jean and Hall, 2001). We previously showed that 2AP fluorescence detects base-flipping at the internal separation pin (Gaubitz et al., 2021), and here we employ the same assay to probe the external separation pin. To specifically probe melting at the external separation pin, we used 5' recessed DNA that does not bind the central chamber (Ellison and Stillman, 2003), and thus would not be flipped by the internal separation pin. We observe a strong enhancement of 2AP fluorescence when this DNA is mixed with RFC, PCNA and ATPYS (Supplemental Figure 1.4). This result indicates that the DNA binds and the terminal base of the 5' recessed end is flipped. This fluorescence enhancement is dependent on ATP analog. Because the external DNA binding site is only formed upon ATP-dependent crab-claw opening, this suggests that the melting occurs at this site. Therefore, we confirm that this melting occurs in solution.

The second DNA binding site is intriguingly close to the A-gate, which serves as the exit channel for the template overhang of the internally bound p/t-DNA. The template strand of the internallybound DNA is positioned in similar fashion as we observed in our other structures of yeast RFC bound to p/t-DNA (Gaubitz et al., 2021), and the last visible nucleotide of overhang is proximal to the flipped base of the second DNA that is positioned in the Agate. Moreover, these two strands are in the same polarity ( 3 ' to $\left.5^{\prime}\right)$. This led us to hypothesize that the second DNA binding site 
represents a mechanism for RFC to bind to DNA with singlestranded gaps (Figure 2C).

\section{RFC binding to gapped DNA}

We hypothesized that the second DNA binding site promotes RFC binding of duplex DNA with single-stranded gaps. To test this hypothesis, we measured RFC's ATPase rate in the presence of PCNA and various potential DNA substrates. ATPase activity is a reasonable proxy for clamp loading because ATP hydrolysis is triggered in the final stages of the loading reaction (Anderson et al., 2009; Liu et al., 2017; Marzahn et al., 2014; Sakato et al., 2012; Trakselis et al., 2003).

We observed stimulation of ATPase activity with DNA constructs containing ssDNA gaps ranging from ten to one nucleotide in length, clearly indicating binding of gapped DNA into the central chamber (Figure 2D). However, the stimulation across all the gapped substrates is lower than observed for p/t-DNA and is not uniform across all gap sizes. ATPase activity decreases with smaller gap size until it reaches a minimum activity at a 4nucleotide gap, then increases again at very small gaps. The ATPase versus gap size profile is remarkably smooth with one glaring exception: the activity from 6-nucleotide gapped DNA is approximately twice as high as one would expect based on the trend. We noted that a 6-nucleotide gap is predicted to be the ideal length to bridge between the internal and external DNA binding sites (Figure 2C).

We wondered about the relationship between gap size and DNA melting, and whether smaller gap sizes require more melting than larger gap sizes. Therefore, we probed melting activity with gapped DNA labeled with 2AP on the primer strand. We used 2AP adjacent to the 3 ' end of the primer strand (i.e. the " $p=-1$ " position) to probe gapped DNA because we hypothesized that melting of multiple base-pairs might be necessary to generate enough ssDNA to span the distance between the internal and external DNA sites. Indeed, we observe significant ATP-dependent fluorescence changes in substrates with ssDNA gaps of four, five, and six nucleotides (Figure 2E). Intriguingly, the fluorescence change is greatest for the 4-nucleotide gapped DNA, suggesting that the construct with the shortest ssDNA segment required the most base-flipping.

To elucidate how RFC binds to gapped DNA, we determined the structures of RFC:PCNA bound to DNA constructs with 6- and 5-nucleotide ssDNA gaps. We chose these gap sizes because we predict that the 6-nucleotide gap will bind without the need to melt much duplex, while the 5-nucleotide gap should be too short to bind without melting DNA or altering the clamp loader structure to accommodate the shorter linker. We determined the structures of RFC:PCNA bound to 5- and 6-nucleotide gapped DNAs to 3.0and 3.3-Å overall resolution (Figure 3 A\&B; Supplemental Figures $3.1 \& 3.2)$.

We find that both structures exhibit the $p / t$ duplex bound in the internal site, and the non-p/t duplex bound at the external DNA binding site. In the 5-gap and 6-gap structures, there is clear density for a single-stranded region of the template strand that connects the two duplex regions (Figure 3A\&B). The ssDNA linker interacts with a series of mostly conserved residues from the AAA+ (P461, R464), Collar (P551, F552, F587), and A' domains (F666, L670, S674, R681) of the A subunit, with some additional contributions from the E subunit (S79, R81, N104) (Figure 3C; Supplemental Figure 1.3). The ssDNA region traverses the same path that the template overhang does in our structures bound to $\mathrm{p} / \mathrm{t}-\mathrm{DNA}$ (Supplemental 3.3A). These results confirm our hypothesis that the external DNA binding site facilitates binding to DNA with small ssDNA gaps.

The ssDNA region in both the 5-gap and 6-gap structures is six nucleotides long, indicating that the 5-gap DNA must have melted at least one base. Indeed, for 5-gap DNA we see clear density for base-flipping of the 3' end of the primer strand in the internal DNA binding site (Figure 3D\&F), similar to what we previously observed for p/t-DNA (Gaubitz et al., 2021). On the other hand, for 6-gap DNA, we observe scant density for flipping of the 3' end (Figure 3D\&E). Neither the 5-gap nor the 6-gap structures show any sign of base-flipping at the external separation pin (Supplemental Figure 3.3B\&C).

\section{RFC binding to nicked DNA}

Because ssDNA gaps of 5- or 6-nucleotides in length can be readily accommodated between the two different DNA binding sites without melting at the external separation pin, we asked if RFC can bind nicked DNA. We examined nicked DNA because it is the smallest gap possible. We tested binding of RFC:PCNA to fully duplex DNA containing a single nick using 2AP fluorescence. We placed the 2AP probe at the 3" end of the primer strand (" $p=0$ " position) to monitor DNA binding and base-flipping in the internal DNA binding site. We observe a large increase in 2AP fluorescence in the presence of RFC:PCNA, greater than the fluorescence increase we observe with standard p/t-DNA (Figure 4A). This fluorescence increase is dependent on the presence of ATP analog, indicating that it requires binding to RFC. Therefore, we observe that the RFC:PCNA:ATPYS complex can stably bind to nicked DNA and melt the 3' end of the primer strand. This effect is not dependent on the presence of a 5' phosphate in the nonprimer strand, indicating that this moiety is not necessary for the base-flipping at the $3^{\prime}$ end of the primer strand, despite its importance in binding to the BRCT domain (Allen et al., 1998; Kobayashi et al., 2006, 2010).

To reveal how RFC binds to nicked DNA, we determined the cryo-EM structure of RFC:PCNA:ATP $\gamma S$ bound to nicked DNA to 3.7- $\AA$ - overall resolution (Figure 4B; Supplemental Figure 4.1; Supplemental Table 1). We again observe duplex DNA bound in both the internal and external sites. Unlike the 5-gap and 6-gap structures that exhibit a six nucleotide ssDNA span that links the two duplexes, we observe a ssDNA stretch of five nucleotides in the nicked DNA structure (Figure 4C). The ssDNA is more taut in the nicked DNA structure, reflecting the mechanical stress that the DNA has undergone to fit within both binding sites.

We observe DNA melting at both separation pins to create the ssDNA gap. We observe clear density for three melted nucleotides at the internal separation pin, with the nucleotides extruded through a cryptic channel that only appears upon RFC opening (Figure 4D) (Gaubitz et al. 2021). We also observe one melted nucleotide at the external separation pin (Figure 4E). Therefore, to account for the five nucleotides of ssDNA stretching between the two sites, there must be one additional melted basepair that we cannot directly observe. We assigned the nucleotide sequence of the DNA based on size of the density for the bases (i.e. purines vs. pyrimidines), and this assignment matches the melting of two nucleotides at the external site. Despite the ambiguity about exactly how much DNA each site can melt, we 
A

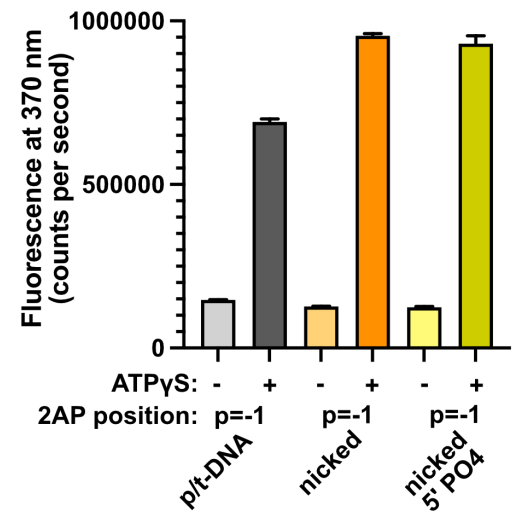

D



B
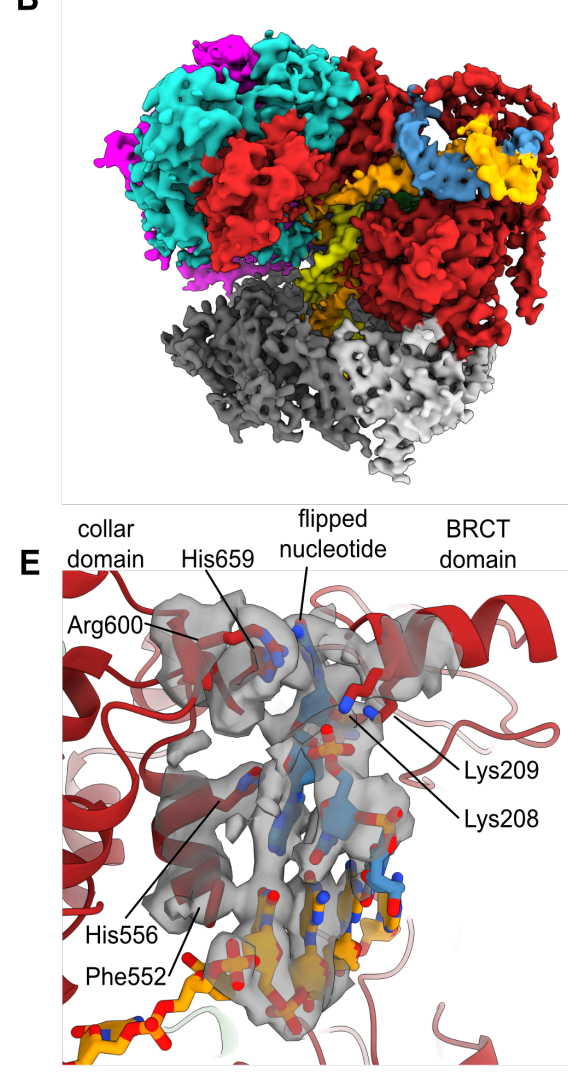

C

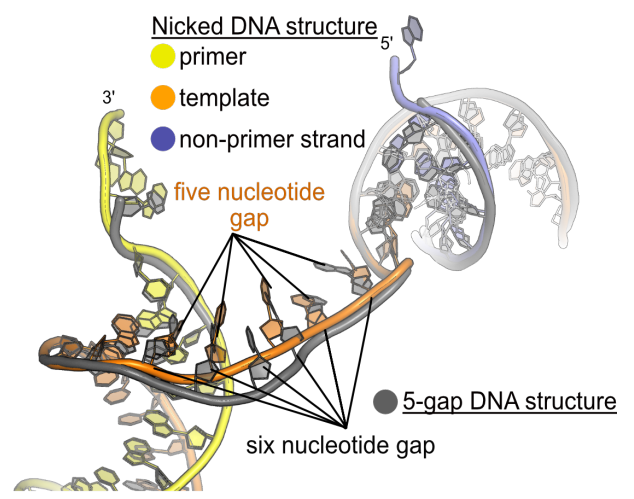

$\mathbf{F}$

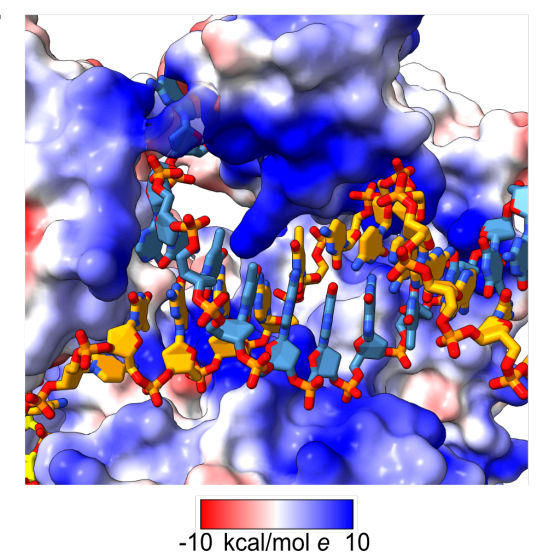

Figure 4: RFC:PCNA binding to nicked DNA. (A) RFC melts the primer 3' end in nicked DNA. 2AP fluorescence at the primer=-1 position (probe adjacent to the flipped base) showing that the primer strand exhibits even more melting than observed in p/t-DNA. The presence of a 5' phosphate on the non-primer strand does not appear to affect base-flipping. (B) Cryo-EM reconstruction of the complex of RFC:PCNA bound to nicked DNA. (C) The nicked DNA contains a ssDNA gap of five nucleotides linking the two duplex binding sites. This is shorter than the structure with 5-gap DNA (gray), which has a six nucleotide long ssDNA linker. (D) At least three base pairs have been melted at the internal separation pin. (E) At least one base pair is melted at the external separation pin. (F) The flipped nucleotide of the non-primer strand is in a highly electropositive environment to stabilize the backbone.

unambiguously show that the external DNA binding site can also unwind DNA to allow RFC to bind nicked DNA.

The melted region of the non-primer strand is in a channel formed between the BRCT domain, the AAA+ module, and the collar. This channel is lined with electropositive residues (R174, K190, K209, R511, H556, K557, R600 \& H659), most of these residues presumably interact favorably with the backbone of the displaced strand (Figure 4F). Like in our 2 p/t-DNA reconstruction, His659's role is for stacking with the base of a melted nucleotide. This residue is conserved as aromatic and most of the other residues are highly conserved as basic in eukaryotes, indicating that both this stacking and electropositive channel are important for function (Supplemental Figure 1.3). The melted nucleotide contacts the BRCT domain's pocket for binding a 5' phosphate (Figure 4E).

We observe no ATP hydrolysis in any of the active sites of the nicked DNA structure, establishing that this melting does not require ATPase activity. Moreover, the conformation of RFC bound to nicked DNA resembles those bound to 6-gapped and 5gapped DNA in all other major respects. Because ATP hydrolysis is typically coupled to a conformational change in AAA+ATPases, this further supports that indicating that the melting does not require ATPase activity.

\section{Deletion of the BRCT domain disrupts response to DNA damage}

We hypothesized that the external DNA binding site is used for loading PCNA at gapped or nicked DNA structures in the cell, which typically arise as Ip-BER intermediates. These intermediates are structures with either a nick or a small (2-12 nucleotide) gap of ssDNA (Sattler et al., 2003), and they require RFC to load PCNA for efficient repair (Matsumoto, 2001; Matsumoto et al., 1999; Pascucci et al., 1999; Sattler et al., 2003; Woodrick et al., 2017). To interrogate how the BRCT domain affects cellular function, we used an RFC complementation system, where the only copy of RFC1 is supplied on a plasmid. We used a series of mutagen challenges to examine if Ip-BER is likely affected and if other DNA metabolic pathways are also affected. We used methyl methanesulfonate (MMS; an alkylating reagent that causes damage most commonly repaired by base excision repair), hydroxyurea (HU; which inhibits DNA synthesis by lowering supplies of deoxyribonucleotides), and ultraviolet radiation (UV; which causes DNA damage that is usually repaired through nucleotide excision repair) (Sinha and Häder, 2002; Yu and Lee, 2017; Matsumoto, 2001). We found that the RFC1$\triangle B R C T$ construct exhibits a growth defect when in combination 
with application of the mutagen MMS, but not with HU or UV (Figure 5). Because melting of DNA is highly dependent on temperature (Yin et al., 2014), we repeated these assays at various temperatures from $18^{\circ} \mathrm{C}$ to $37^{\circ} \mathrm{C}$. The growth defect is seen across a range of MMS concentrations and across a range of growth temperatures, but is not seen with HU and UV at any temperature (Supplemental Figure 5.1). Therefore, we see a growth defect in yeast lacking the Rfc1 BRCT domain that is specific to the damage induced by MMS.

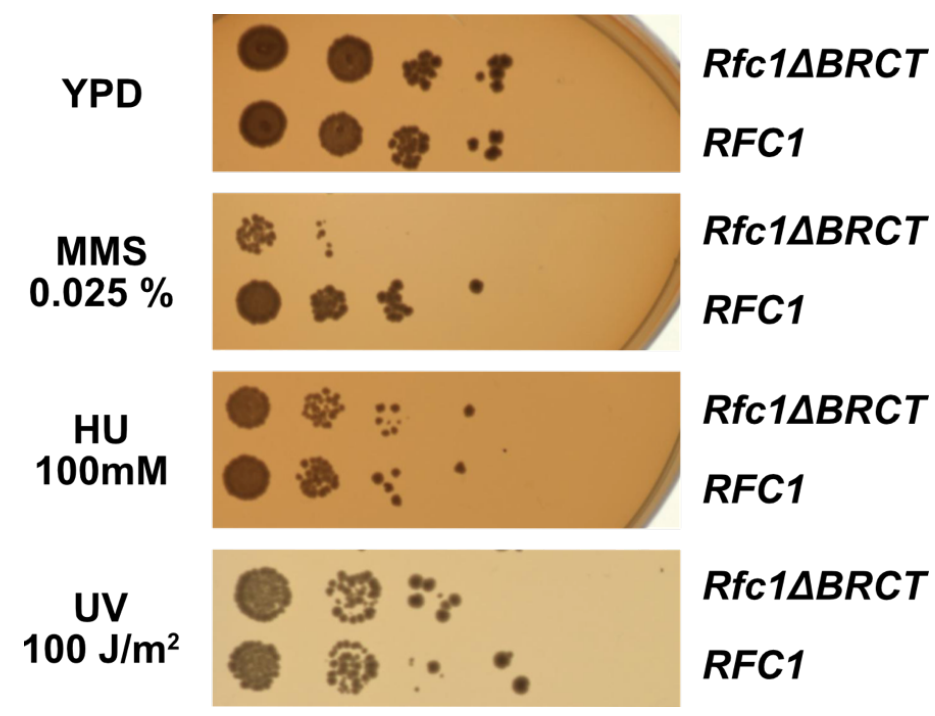

Figure 5: Deletion of the BRCT domain of Rfc1 results in a DNA damage repair defect. Yeast carrying the sole copy of the RFC1 gene on a plasmid were subjected to various treatments that stress DNA metabolism. Rfc1- $\triangle \mathrm{BRCT}$ yeast exhibit a growth defect with the DNA alkylating agent methyl methanesulfonate (MMS), but not with hydroxyurea (HU) or ultraviolet radiation (UV). Various other conditions are shown in Supplemental Figure 5.1.

\section{DISCUSSION}

Here we reveal a second DNA binding site on the external surface of RFC. This site expands RFC's repertoire of targets by facilitating binding to DNA that is either nicked or contains small ssDNA gaps. The external site is composite, consisting of three different domains of the A subunit. This composite nature allows more flexibility in binding to substrates. Furthermore, the binding site is only found in the Open conformation of RFC and is sterically blocked in the Autoinhibited conformation, thereby coupling DNA binding to RFC conformation. In these ways, the second DNA binding site has ramifications for the mechanism of substrate recognition, as well as the evolution of alternative clamp loader activities.

\section{External DNA binding site is similar to that of Rad24-RLC}

The external DNA binding site closely resembles the primary DNA binding site in Rad24-RLC. The "alternative" clamp loader Rad24RLC differs from RFC by the A-subunit Rfc1, which is swapped out for the Rad24 protein (Majka and Burgers, 2004). This seemingly small difference radically changes the loading specificity, as Rad24-RLC loads a different sliding clamp (the 9-
1-1 complex) onto DNA of opposite polarity (I.e. with a recessed 5' end) (Ellison and Stillman, 2003; Majka and Burgers, 2004). Recent structures of Rad24-RLC bound to 9-1-1 and 5'-recessed DNA have revealed the surprising finding that the duplex DNA region is bound on the external surface of the A-subunit Rad24, with the 3' ssDNA overhang snaking through the A-gate into the central chamber (Figure 6A) (Zheng et al. 2021; Castaneda et al. 2021).

Our structures presented here lead to an obvious mechanism for evolution of Rad24-RLC's activity. The classical clamp loader RFC is the likely progenitor of Rad24-RLC. Because the Rfc1 subunit already had the ability to bind DNA with a recessed 5' end, the evolution of Rad24's ability to specifically recognize and load clamps at this DNA architecture is trivial. The DNA binding site of Rad24-RLC also has a region that resembles the external separation pin of Rfc1, although Rad24-RLC has not been observed to melt DNA. It remains to be seen if melting is conserved, because such an activity could facilitate loading of 91-1 onto the recessed 5' ends at short ssDNA gaps.

Because the other two known alternative clamp loaders (Ctf18RLC and Elg1-RLC) also differ from RFC by only the A subunit, our findings highlight that similar evolutionary paths may have led towards their DNA substrate specificities. Future studies will reveal if this is true, and if so, what mechanisms are shared amongst the various clamp loaders.

\section{RFC has two DNA separation pins}

We find that RFC has two separation pins: one in the interior that can melt three nucleotides from the primer 3' end, and an external site that can melt at least one base of DNA. Both separation pins in Rfc1 are conserved across eukaryotes (Supplemental Figure 1.3), indicating that these DNA melting activities are broadly used. Melting at the external site allows for nicked DNA (and perhaps small ssDNA gaps) to bind by creating and/or extending a ssDNA gap that can fit through the A-gate. The external separation pin relies on a channel to funnel the extruded strand. This channel consists of residues from the BRCT domain (K190, K209), the $\mathrm{AAA}+$ module (R511), and the collar domain (H556, K557, R600, \& H659) of Rfc1. This composite nature of the external DNA binding site likely makes it more pliable than the internal site, which may allow for novel means of regulation.

Neither separation pin appears to require ATP hydrolysis in order to melt DNA. We previously established that the internal site melts a single base pair without hydrolyzing ATP (Gaubitz et al., 2021). While formally possible that melting more than one nucleotide requires ATP hydrolysis, our data would argue that this is likely not the case. First, we observe no ATP hydrolysis in the structure of RFC bound to nicked DNA, where five bases are melted. Second, ATP hydrolysis resets the clamp loader structure (Hingorani and O'Donnell, 1998; Turner et al., 1999), and the open ATP-bound conformation is the only one capable of forming the external DNA binding site. While the idea of an ATPase melting DNA without hydrolyzing ATP might seem unusual, there are numerous examples in the literature of other proteins with this ability. For example, non-NTPase proteins such as CRISPR nucleases and SSDNA Binding Protein can melt far longer stretches of DNA (Jore et al., 2011; Roy et al., 2009; Szczelkun et al., 2014). Moreover, ATP-dependent helicases can melt substantial amounts of DNA in the absence of ATP hydrolysis (Lohman and Fazio, 2018; Reynolds et al., 2015). In all of these 
cases, the energy for melting DNA comes from binding energy. Thus, we propose that RFC also uses binding energy to melt DNA at both separation pins.

\section{Role for the BRCT domain}

Our structures provide the first visualizations of the RFC BRCT domain in the context of an intact clamp loader. We find that the BRCT domain plays an important role in binding DNA at the external DNA binding site. The BRCT domain is docked on top of the $A A A+$ module of the $A$ subunit, and is tethered through a long helix (Figure 1A\&B). The density for the BRCT domain is not as strong as for the other domains of RFC, suggesting that the BRCT domain may sample different orientations. This could provide the external binding site greater pliability in DNA docking, which may provide novel means of regulation. Although it is tempting to claim that this means that the BRCT binds DNA weakly, the isolated BRCT domain binds DNA very tightly, with a $\mathrm{K}_{\mathrm{d}}$ of $\sim 10 \mathrm{nM}$ (Kobayashi et al., 2006). Therefore, the BRCT domain could act as a flexible tether to initially bind DNA with high affinity before docking onto the core of the clamp loader.

The BRCT domain binds DNA in a different orientation when in RFC than in isolation. The BRCT domain prefers DNA with a 5 ' phosphate end, particularly if there is a 3' ssDNA overhang (Allen et al., 1998; Fotedar et al., 1996; Kobayashi et al., 2006, 2010). How the isolated BRCT domain binds to DNA was determined using a combination of NMR restraints and modeling in HADDOCK (Kobayashi et al., 2010). The DNA binding mode in isolation is incompatible with the conformation of RFC that we observe in our structures, as the DNA would clash with the collar domain (Supplemental Figure 6.1). Therefore, the binding mode observed in isolation is likely to be only used when the BRCT domain is loosely tethered to the core clamp loader complex. This could provide the BRCT domain the ability to capture DNA at early stages of the loading reaction, possibly before PCNA has bound (Figure 6B). To avoid clashing with the collar domain, the BRCT domain must change its grip on DNA upon docking to the AAA+ module. This may play a role in DNA melting and subsequent binding in the central chamber. In support of this hypothesis, the isolated BRCT domain inhibits RFC's loading of PCNA at gapped DNA sites (Fotedar et al., 1996).

The BRCT domain is also likely to function as a protein-protein interaction hub, as do most BRCT domains (Leung and Glover, 2011). There is evidence that at least two proteins, DNA ligase I and the protease FAM111A, bind to RFC using the BRCT domain (Hoffmann et al., 2020; Levin et al., 2004). Thus, the coupling of BRCT docking and clamp opening provides a potential mechanism for regulating binding of RFC partner proteins.

We observe that deletion of the BRCT domain causes a growth defect in yeast grown in the presence of the DNA-alkylating agent MMS (Figure 5). Previous work showed that deletion of the entire $\mathrm{N}$-terminal 273 amino acids resulted in sensitivity to MMS (Gomes et al., 2000). This deleted region encompasses the BRCT domain, but also includes several other regions as well. We extend that previous analysis to show that this defect can be specifically localized to the BRCT domain. Furthermore, we observe no growth defect when Rfc1- $\triangle \mathrm{BRCT}$ yeast are treated with UV or HU.

Based on our nicked and gapped DNA structures along with this phenotype, we propose that the loss of the BRCT domain perturbs Ip-BER by disrupting PCNA loading at nicks or small gaps. The damage induced by MMS is primarily repaired by BER
(Lindahl and Wood, 1999; Wyatt and Pittman, 2006), whereas the damage caused by $\mathrm{HU}$ and UV is primarily repaired by other pathways (Petermann et al., 2010; Sinha and Häder, 2002; Yu and Lee, 2017). During $S$ phase, the cell primarily relies on the Ip-BER subpathway, which requires RFC to load PCNA at nicks and small ssDNA gaps (Matsumoto, 2001; Matsumoto et al., 1999; Pascucci et al., 1999; Sattler et al., 2003; Woodrick et al., 2017). Because the BRCT domain assists in binding to gapped or nicked DNA, we speculate that the loss of the BRCT domain results in less effective Ip-BER. Future experiments will test this hypothesis.

\section{A speculative model for binding of nicks and small ssDNA gaps}

We have synthesized the available biochemical and structural data to derive a mechanistic model for how nicked or gapped DNA structures bind to the clamp loader (Figure 6B). The flexibly tethered BRCT domain increases the collision radius of RFC, thereby increasing the likelihood that RFC contacts DNA. Furthermore, the BRCT domain's intrinsic specificity for the 5' end of DNA gives it preference in orienting gapped or nicked DNA correctly (Allen et al., 1998; Fotedar et al., 1996; Kobayashi et al., 2006, 2010). Binding DNA at the BRCT domain anchors DNA close to the RFC core machinery, thereby increasing the local concentration dramatically. Because the external binding site on the shoulder of Rfc1 is sterically blocked in the Autoinhibited conformations, the AAA+ module must bind the sliding clamp prior to the BRCT domain docking onto the shoulder region of RFC. When the AAA+ module binds PCNA, the complex undergoes the crab-claw opening that both opens the sliding clamp for DNA entry as well as exposes the second DNA binding site on the shoulder of Rfc1 (Gaubitz et al., 2021). In this way, the clamp loader maintains ordered clamp binding, opening, and loading despite binding to DNA prior to the sliding clamp. After RFC opens, the DNA-bound BRCT domain can now dock onto the shoulder region. The steric clash between the BRCT-bound DNA and the external separation pin necessitates an alteration in the manner in which the BRCT engages DNA. Thus, docking of DNA-bound BRCT to the shoulder may facilitate unwinding at the external separation pin. Once DNA is fully engaged to the newlyformed external DNA binding site, RFC becomes locked into the Open conformation and the DNA is co-localized near the A-gate. In this sense, the duplex DNA bound at the external site can act as an allosteric regulator of RFC. Once sufficient DNA is melted at the external site to create a long enough ssDNA linker, duplex DNA then traverses the A-gate into the central chamber. As DNA enters the central chamber, DNA reorients and the 3' end of the primer melts at the internal separation pin of Rfc1. Duplex DNA binding in the chamber activates ATPase activity, possibly through the flipping of the "arginine switch." This conserved arginine holds the catalytic glutamate in an inactive conformation; once DNA binds, the arginine grips DNA and releases the glutamate into an active conformation (Kelch et al., 2011). In support of this hypothesis, we observe that the arginine switch residue is flipped into the active conformation in most of our structures (Supplemental Figure 6.2). The DNA also rigidifies the AAA+ spiral, which is likely a key factor in ATPase activity (Subramanian et al., 2021). Finally, ATP hydrolysis and $P_{i}$ release triggers clamp closure and ejection of the clamp loader. Our model makes numerous predictions for the clamp loading reaction that will need to be tested in future studies. 
A

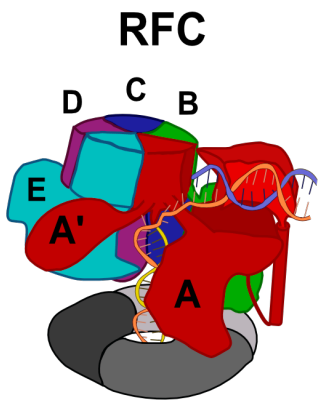

B

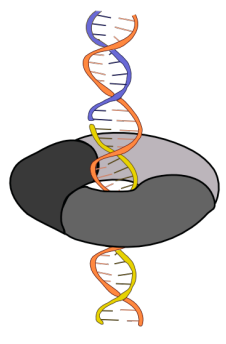

$A D P+P_{i}$ release

ATP binding

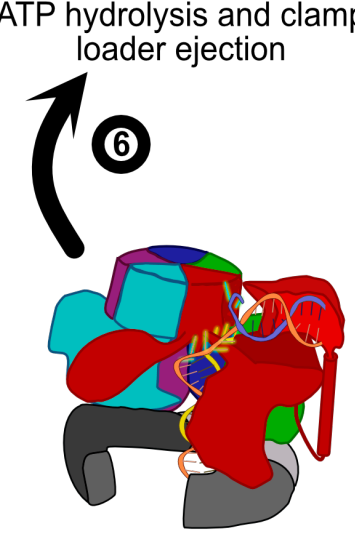

p/t-DNA enters A-gate, melting at internal separation pin

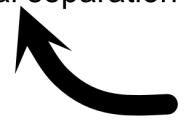

(5)

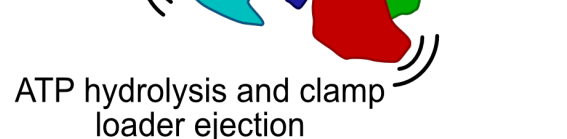

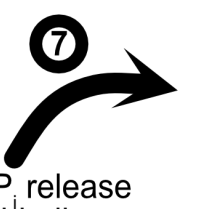

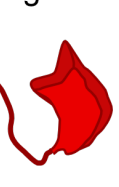

autoinhibited

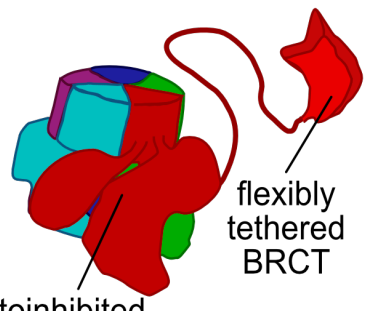

RFC

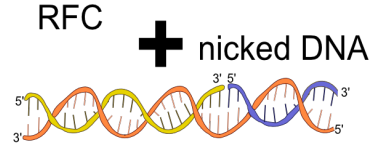

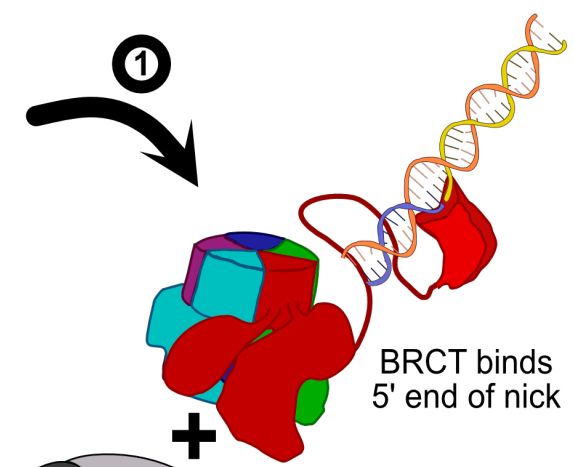
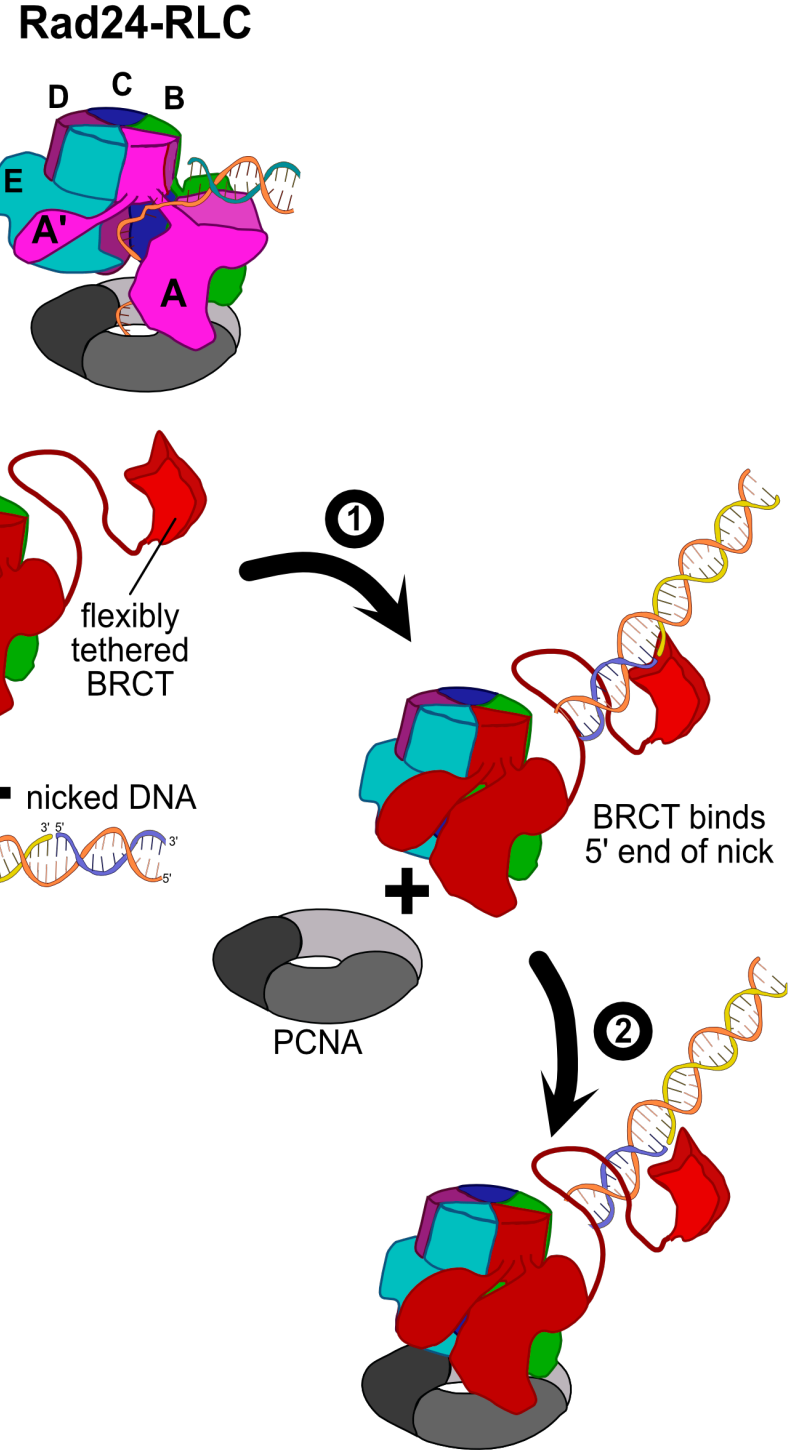

PCNA binds RFC



(4) DNA melting at external separation pin

Figure 6: Insights into clamp loader evolution and mechanism from the discovery of the external DNA binding site. (A) The external binding site of RFC is similar to that recently reported for Rad24-RLC (Zheng et al. 2021; Castaneda et al. 2021), suggesting that a straightforward mechanism for the evolution of Rad24-RLC's ability to load clamps at 5'-recessed DNA. (B) A speculative mechanism for the RFC's mechanism for loading PCNA at nicked DNA. Melted bases are shown in glowing green. See text for detailed description. 


\section{MATERIALS AND METHODS}

\section{Protein Expression and Purification\}

RFC was purified as described previously (Gaubitz et al. 2021). Briefly, pET(11a)-RFC[2+3+4] and pLANT-2/RIL-RFC[1+5] were transformed into BL21(DE3) E. coli cells (Millipore). For protein expression, transformants were grown in 4 liter of prewarmed terrific broth medium with $50 \mu \mathrm{g} / \mathrm{mL}$ kanamycin and $100 \mu \mathrm{g} / \mathrm{mL}$ ampicillin at $37^{\circ} \mathrm{C}$ and induced with IPTG at an optical density of 0.8. Expression was continued at $18{ }^{\circ} \mathrm{C}$ for $16-18$ hours. Cells were pelleted and resuspended in $300 \mathrm{ml}$ lysis buffer $(30 \mathrm{mM}$ Hepes- $\mathrm{NaOH}$ pH 7.5, 250 mM NaCl, 0.25 mM EDTA, 5\% glycerol, $2 \mathrm{mM}$ DTT, $2 \mu \mathrm{g} / \mathrm{mL}$ aprotinin, $0.2 \mu \mathrm{g} / \mathrm{mL}$ pepstatin, $2 \mu \mathrm{g} / \mathrm{mL}$ leupeptin, $1 \mathrm{mM}$ PMSF). RFC was purified by chromatography over $10 \mathrm{~mL}$ SP-Sepharose ( $80 \mathrm{~mL}$ gradient of 300-600 mM NaCl) and $10 \mathrm{~mL}$ Q-Sepharose ( GEHealthcare, $40 \mathrm{~mL}$ gradient of $150-$ $500 \mathrm{mM} \mathrm{NaCl}$ ). Fractions of RFC were pooled and dialyzed overnight into $30 \mathrm{mM}$ Hepes- $\mathrm{NaOH}$ pH 7.5, $250 \mathrm{mM} \mathrm{NaCl}, 5 \%$ glycerol, and $2 \mathrm{mM}$ DTT.

PCNA was purified as described previously (Gaubitz et al. 2021). Briefly, BL21(DE3) E. coli cells were transformed with a 6xHisPPX-PCNA-expressing pET-28 vector (PPX=Precission ${ }^{\mathrm{TM}}$ protease). For protein expression, 1 liter of induced cells was grown overnight at $18{ }^{\circ} \mathrm{C}$ in terrific broth medium with $50 \mu \mathrm{g} / \mathrm{mL}$ kanamycin. Cells were pelleted and resuspended $30 \mathrm{mM}$ Hepes $\mathrm{pH} 7.6,20 \mathrm{mM}$ imidazole, $500 \mathrm{mM} \mathrm{NaCl}, 10 \%$ glycerol, and $5 \mathrm{mM}$ $\beta$-mercaptoethanol. Upon cell lysis, centrifugation, and lysate filtration, the lysate was applied to a $5 \mathrm{~mL}$ HisTrap FF column (GEHealthcare). The column was washed with a $1 \mathrm{M} \mathrm{NaCl}$ buffer and subsequently with a $50 \mathrm{mM} \mathrm{NaCl}$ buffer. PCNA was eluted with $500 \mathrm{mM}$ imidazole. The eluted protein was cleaved with Precission ${ }^{\mathrm{TM}}$ protease. The cleaved protein was applied to a $5 \mathrm{~mL}$ HiTrap Q HP column (GE Healthcare), from which it was eluted with $2 \mathrm{M} \mathrm{NaCl}$ in a $100 \mathrm{~mL}$ gradient. RFC-containing fractions were dialyzed against $30 \mathrm{mM}$ Tris $\mathrm{pH} 7.5,100 \mathrm{mM} \mathrm{NaCl}$, and $2 \mathrm{mM}$ DTT. Purified RFC was concentrated, aliquoted and frozen in liquid nitrogen for storage at $-80^{\circ} \mathrm{C}$.

\section{Crosslinking}

RFC and PCNA were mixed in a 1:1 molar ratio and buffer exchanged into $1 \mathrm{mM}$ TCEP, $200 \mathrm{mM} \mathrm{NaCl}, 25 \mathrm{mM}$ Hepes- $\mathrm{NaOH}$, $\mathrm{pH} 7.5$, and $4 \mathrm{mM} \mathrm{MgCl}_{2}$. The protein complex was diluted to 3 $\mu \mathrm{M}$ and $1 \mathrm{mM}$ ATP $\gamma \mathrm{S}$ was added to the protein complex and incubated for 2 min. Subsequently, $7 \mu \mathrm{M}$ 5-gapped, 6-gapped, or nicked DNA was added and incubated for another $1 \mathrm{~min}$. The sequences of the DNA oligonucleotides are listed in Supplement Table 2. The crosslinking reaction was started with $1 \mathrm{mM} \mathrm{BS3,}$ incubated for $15 \mathrm{~min}$ at room temperature, and neutralized with Tris-HCl.

\section{Electron Microscopy}

Cryo-EM sample preparation
Quantifoil R 0.6/1 grids were washed with ethyl acetate, and glow discharged with Pelco easiGlow for $60 \mathrm{~s}$ at $25 \mathrm{~mA}$ (negative polarity). $2.8 \mu \mathrm{L}$ of the sample with p/t DNA and $3.5 \mu \mathrm{L}$ of the samples with gapped or nicked DNA were applied to grids at $10^{\circ} \mathrm{C}$ and $95 \%$ humidity in a Vitrobot Mark IV (FEI). Samples were blotted with a force of 5 for $5 \mathrm{~s}$ after a $2 \mathrm{~s}$ wait and plunged into liquid ethane.

\section{Cryo-EM data collection}

RFC:PCNA with p/t-DNA was imaged on a Titan Krios operated at $300 \mathrm{kV}$ and equipped with a K3 detector at $81000 \times$ magnification and a pixel size of $0.53 \AA$ in super-resolution mode. 4499 micrographs were collected with a target defocus of -1.2 to -2.3 and a total exposure of $\sim 40 \mathrm{e}-/ \AA^{2}$ per micrograph averaging 30 frames.

RFC:PCNA:6-gapped DNA was imaged on a Talos Arctica at 200 $\mathrm{kV}$, at $45000 \times$ magnification and a pixel size of 0.435 (bin=0.5), using a K3 detector in super-resolution mode. The data was collected with a target defocus range of -1 to $-2.2 \mu \mathrm{m}$, and a total exposure of $\sim 45 \mathrm{e}-/ \AA^{2} .4039$ micrographs were recorded using the "multi-shot" method, applying image shift and beam tilt to collect 1 shot per hole and 9 holes per stage move in $\sim 17.5 \mathrm{hr}$ with SerialEM (Mastronarde 2003). The dose rate is 22.56 electrons/unbinned pixel/sec.

Both RFC:PCNA:5-gapped DNA and RFC:PCNA:nicked DNA were imaged on a Titan Krios operated at $300 \mathrm{kV}$ and equipped with a Gatan energy filter at a slit width of $20 \mathrm{eV}$ at $105000 \mathrm{x}$ magnification and a pixel size of $0.415 \AA$ (bin=0.5), using a K3 detector in super-resolution mode.

The RFC:PCNA:5-gapped DNA data was collected with a target defocus range of -1 to $-2.2 \mu \mathrm{m}$, and a total exposure of $47.7 \mathrm{e}-$ $/ \AA^{2}$. Multi-shot of $1 \times 15$ (single shot $x 15$ holes) was used to record 5121 micrographs in $\sim 25 \mathrm{hr}$ with a dose rate of 24.70 electrons/unbinned pixel/sec.

The RFC:PCNA:Nicked DNA data was collected with a target defocus range of -1 to $-2 \mu \mathrm{m}$, and a total exposure of $48.7 \mathrm{e}-/ \AA^{2}$. Multi-shot of $1 \times 9$ (single shot $\times 9$ holes) was used to record 5651 micrographs in $\sim 19 \mathrm{hr}$ with a dose rate of 24.70 electrons/unbinned pixel/sec.

\section{Data Processing}

Data processing for the RFC:PCNA:2p/tDNA was performed exactly as described previously (Supplemental Figure 1.1) (Gaubitz et al. 2021). Data processing of the datasets with nicked or gapped DNA was performed with minor modifications as follows (Supplemental Figure 3.1, 3.2, and 4.1). Micrograph frames were aligned in IMOD (Kremer et al., 1996) with 2x binning, resulting in a pixel size of $0.83 \AA /$ pixel. Particle picking was performed using cisTEM (Grant et al. 2018). Following particle picking, particles were extracted with a box size of 240 pixels (dataset with $\mathrm{p} / \mathrm{t} \mathrm{DNA}$ ) or 320 pixels (all other datasets) and subjected to 2D classification. (Supplemental Figure 3.1A\&B, 3.2A\&B, and 4.1A\&B) Particles from classes with well defined features were selected for processing in Relion 3.1. Coordinates 
and micrographs were imported into Relion 3.1 (Zivanov et al., 2018), CTF parameters were re-estimated with CtfFind-4.1 (Rohou and Grigorieff 2015) and particles were subjected to several rounds of $3 D$ classification. For 3D classification of the dataset with the 6-gapped DNA, the down-filtered RFC:PCNA:2p/tDNA cryo-EM reconstruction was used as reference, for $3 \mathrm{D}$ classification of the datasets with the 5-gapped and nicked DNA, the downfiltered reconstructions of RFC:PCNA:6gapped DNA and RFC:PCNA:5gapped DNA, respectively, were used as reference (Supplemental Figure 3.1C, 3.2C, and 4.1C). All references were downfiltered to $50 \AA$. In the dataset of RFC:PCNA bound to 6-gapped DNA we observe classes of RFC bound to opened or closed PCNA. However, for further refinement we focused on classes which represented the highest number of particles and also had the highest resolution. In these classes, PCNA is always in the closed conformation across the different datasets (Supplemental Figure 3.1C, 3.2C, and 4.1C. The cryo-EM density was postprocessed in Relion for estimating the resolution and density modified with PHENIX for model building and refinement ((Terwilliger et al., 2020) Supplemental Table 1). Model information was not used for density modification.

\section{Model Building and Refinement}

The structure of yeast RFC bound to closed PCNA and p/t DNA (PDB ID: 7TID) was used for initial fitting of the cryo-EM reconstruction of RFC:PCNA bound to 6-gapped DNA. All subunits were split into globular domains and fitted into the cryoEM density with UCSF Chimera (Pettersen et al., 2004). For building the BRCT domain and the adjacent alpha-helix, the AlphaFold model (Jumper et al. 2021; Varadi et al. 2022) corresponding to these residues was fitted into the cryo-EM density. The model was adjusted in Coot (Emsley and Cowtan, 2004), and the DNA was built in manually. The manually adjusted model of RFC:PCNA:6-gapped DNA was used to rigid body fit the cryo-EM density of RFC:PCNA bound to 5-gapped DNA and the density of RFC:PCNA bound to nicked DNA. The fitted models were adjusted and the DNA was built in manually in Coot. The adjusted models were real-space refined in PHENIX1.19 (Liebschner et al., 2019). UCSF Chimera and Pymol were used for figure generation (DELANO and W. L, 2002; Pettersen et al., 2004; Supplemental Figure 3.1D, 3.2D, and 4.1D; Supplemental Table 1).

The density of RFC:PCNA bound to two p/tDNA was rigid body fitted with the model for RFC:PCNA bound to 5-gapped DNA. The DNA was replaced by $\mathrm{p} / \mathrm{t}$ DNA and an ideal B-form DNA molecule for the externally bound DNA. The flipped bases in proximity to the external separation pin were added manually with Coot. The density did not allow the unambiguous assignment of the exact sequence of the externally bound DNA. Moreover, the PCNA density in proximity to RFC-E is highly distorted, likely owing to a structural heterogeneity of particles in this class with PCNA being bound to RFC in the open and closed form. Therefore, the model was not further refined.

\section{ATPase Assays}

$0.12 \mu \mathrm{M}$ RFC was incubated with a master mix (3 U/mL Pyruvate kinase, $3 \mathrm{U} / \mathrm{mL}$ Lactate dehydrogenase, $1 \mathrm{mM}$ ATP, $670 \mu \mathrm{M}$
Phosphoenol pyruvate, $170 \mu \mathrm{M}$ NADH, $50 \mathrm{mM}$ Tris $(\mathrm{pH} 7.5), 0.5$ $\mathrm{mM}$ TCEP, $5 \mathrm{mM} \mathrm{MgCl}$, $200 \mathrm{mM}$ potassium glutamate, $40 \mathrm{mM}$ $\mathrm{NaCl}), 1 \mu \mathrm{M}$ PCNA, and $0.03 \mu \mathrm{M}$ annealed DNA substrates, whose sequences are listed in Supplemental Table 2. ATPase activity was measured at room temperature with the 2014 EnVison $\AA$ Multilabel Plate Reader to detect NAD+. Rates were obtained from a linear fit of the slopes using GraphPad Prism. For each data point three experimental replicates were performed.

\section{AP Fluorescence}

2-Aminopurine (2AP) fluorescent samples were excited at $315 \mathrm{~nm}$ (5 mm slit width), and emission was detected at $370 \mathrm{~nm}$ (7 mm slit width) with a FluoroMax 4 (Horiba Jobin Yvon Inc). Reactions contained 200nM annealed DNA, $0.5 \mu \mathrm{M}$ RFC, and $2 \mu \mathrm{M}$ PCNA in a solution of $50 \mathrm{mM}$ Hepes- $\mathrm{NaOH}$ pH 7.5, $200 \mathrm{mM} \mathrm{NaCl}, 4 \mathrm{mM}$ $\mathrm{MgCl}_{2}, 1 \mathrm{mM}$ TCEP and were carried out at room temperature. 1 $\mathrm{mM}$ ATP $\gamma S$ was added to the reaction, and measurement was taken after $4 \mathrm{~min}$ of incubation. For each data point three experimental replicates were performed.

\section{Plasmid generation}

The complementation plasmid pRS413-RFC1 contains the entire RFC1 sequence, where Rfc1 is expressed under the control of its own promoter. The $\triangle B R C T$ RFC variant was introduced with sitedirected mutagenesis in pRS413-RFC1, resulting in pRS413Rfc1 $\triangle B R C T$. Residues $154-230$ in RFC1 were replaced by a GSGS linker.

\section{Yeast strain and spot assay}

The $S$. cerevisiae strain used in this study for transformation with pRS413-RFC1 and pRS413-Rfc1 $\triangle B R C T$ and subsequent dissection was obtained from the Dharmacon ${ }^{\mathrm{TM}}$ Yeast Heterozygous Collection and verified by PCR. The genotype is BY 4743 is his $3 \Delta 1 /$ his $3 \Delta 1$ leu2 $\Delta 0 /$ leu $2 \Delta 0$ LYS2/lys $2 \Delta 0$ met15 $\Delta 0 /$ MET15 ura3 $\Delta 0 /$ ura3 $\Delta 0 \quad \Delta$ rfc1::KanMX4/RFC1 (YOR217W). S. cerevisiae culture, transformation, tetrad dissection, were performed as described by Gomes et al., 2000. For the spot assay, yeast was grown on a plate with synthetic medium without histidine at $30^{\circ} \mathrm{C}$ for 2 days, subsequently inoculated into $3 \mathrm{ml}$ synthetic complete-His media and grown for 3-4 hours to an OD of 0.8 . Serial 10 -fold dilutions of the culture starting from OD of 0.2 were plated as $4 \mu \mathrm{l}$ drops onto YPD plates with or without chemical additives $(0.015,0.02,0.025 \%$ methyl methanesulfonate (MMS), 100, $200 \mathrm{mM}$ hydroxyurea (HU)). For UV treatment, the spotted yeast was irradiated with 30 , or 100 $\mathrm{J} / \mathrm{m}^{2}$ using a UVP UV Crosslinker. The plates were imaged after incubating at $18^{\circ} \mathrm{C}$ for 7 days, or at $30^{\circ} \mathrm{C}$ or $37^{\circ} \mathrm{C}$ for 3 days. 3 replicates were done for all conditions.

\section{ACKNOWLEDGMENTS}

The authors thank Drs. C. Xu, KK Song, K. Lee, and C. Ouch for assistance with data collection, and Dr. C. Xu for advice on data processing. We thank Drs. T. Kubota and N. Rhind as well as members of the Kelch, Royer, Munson, Rando, and Schiffer labs for helpful discussions. We thank Dr. Mary Munson for technical support for yeast experiments. This work was funded by NIGMS 
(R01-GM127776). C.G. was supported by an Early and Advanced Postdoc Mobility (grant numbers 168972 and 177859) Fellowship of the Swiss National Science Foundation.

\section{AUTHOR CONTRIBUTIONS}

C.G., X.L., J.P. and B.A.K. designed experiments. C.G. and X.L. performed cryo-EM sample preparations, data collection and processing. C.G., X.L., \& J.P. performed biochemical experiments. C.G., X.L., J.P. and B.A.K. built and refined the atomic models, analyzed the data and wrote the paper. The authors declare no conflict of interest.

\section{REFERENCES}

Allen, B.L., Uhlmann, F., Gaur, L.K., Mulder, B.A., Posey, K.L., Jones, L.B., and Hardin, S.H. (1998). DNA recognition properties of the Nterminal DNA binding domain within the large subunit of replication factor C. Nucleic Acids Res. 26, 3877-3882.

Anderson, S., Thompson, J., Paschall, C., O’Donnell, M., and Bloom, L. (2009). Temporal Correlation of DNA Binding, ATP hydrolysis, and Clamp Release in the Clamp Loading Reaction Catalyzed by the Escherichia coli gamma complex. Biochemistry.

Ason, B., Handayani, R., Williams, C.R., Bertram, J.G., Hingorani, M.M., O'Donnell, M., Goodman, M.F., and Bloom, L.B. (2003). Mechanism of loading the Escherichia coli DNA polymerase III beta sliding clamp on DNA. Bona fide primer/templates preferentially trigger the gamma complex to hydrolyze ATP and load the clamp. J. Biol. Chem. 278, 10033-10040.

Bowman, G.D., O'Donnell, M., and Kuriyan, J. (2004). Structural analysis of a eukaryotic sliding DNA clamp-clamp loader complex. Nature 429, 724-730.

Castaneda, J.C., Schrecker, M., Remus, D., and Hite, R.K. (2021). Mechanisms of loading and release of the 9-1-1 checkpoint clamp.

Choe, K.N., and Moldovan, G.-L. (2017). Forging Ahead through Darkness: PCNA, Still the Principal Conductor at the Replication Fork. Mol. Cell 65, 380-392.

DELANO, and W. L (2002). The PyMOL Molecular Graphics System. Http://www.pymol.org.

Ellison, V., and Stillman, B. (2003). Biochemical characterization of DNA damage checkpoint complexes: clamp loader and clamp complexes with specificity for 5' recessed DNA. PLoS Biol. 1, E33.

Emsley, P., and Cowtan, K. (2004). Coot: model-building tools for molecular graphics. Acta Crystallogr. D Biol. Crystallogr. 60, 2126-2132.

Erzberger, J.P., and Berger, J.M. (2006). Evolutionary relationships and structural mechanisms of AAA+ proteins. Annu. Rev. Biophys. Biomol. Struct. 35, 93-114.

Finkelstein, J., Antony, E., Hingorani, M.M., and O’Donnell, M. (08/2003). Overproduction and analysis of eukaryotic multiprotein complexes in Escherichia coli using a dual-vector strategy. Anal. Biochem. 319, 78-87.

Fotedar, R., Mossi, R., Fitzgerald, P., Rousselle, T., Maga, G., Brickner, H., Messier, H., Kasibhatla, S., Hübscher, U., and Fotedar, A. (1996). A conserved domain of the large subunit of replication factor $C$ binds
PCNA and acts like a dominant negative inhibitor of DNA replication in mammalian cells. EMBO J. 15, 4423-4433.

Frey, M.W., Sowers, L.C., Millar, D.P., and Benkovic, S.J. (1995). The nucleotide analog 2-aminopurine as a spectroscopic probe of nucleotide incorporation by the Klenow fragment of Escherichia coli polymerase I and bacteriophage T4 DNA polymerase. Biochemistry 34, 9185-9192.

Gaubitz, C., Liu, X., Magrino, J., Stone, N.P., Landeck, J., Hedglin, M., and Kelch, B.A. (2020). Structure of the human clamp loader reveals an autoinhibited conformation of a substrate-bound AAA switch.

Proceedings of the National Academy of Sciences 117, 23571-23580.

Gaubitz, C., Liu, X., Pajak, J., Stone, N.P., Hayes, J.A., Demo, G., and Kelch, B.A. (2021). Cryo-EM structures reveal high-resolution mechanism of a DNA polymerase sliding clamp loader.

Gomes, X.V., Gary, S.L., and Burgers, P.M.J. (2000). Overproduction in Escherichia coli and Characterization of Yeast Replication Factor C Lacking the Ligase Homology Domain *. J. Biol. Chem. 275, 1454114549.

Grant, T., Rohou, A., and Grigorieff, N. (2018). cisTEM, user-friendly software for single-particle image processing. Elife 7.

Hingorani, M.M., and O'Donnell, M. (1998). ATP binding to the Escherichia coli clamp loader powers opening of the ring-shaped clamp of DNA polymerase III holoenzyme. J. Biol. Chem. 273, 24550-24563.

Hoffmann, S., Pentakota, S., Mund, A., Haahr, P., Coscia, F., Gallo, M., Mann, M., Taylor, N.M., and Mailand, N. (2020). FAM111 protease activity undermines cellular fitness and is amplified by gain-of-function mutations in human disease. EMBO Rep. 21, e50662.

Jean, J.M., and Hall, K.B. (2001). 2-Aminopurine fluorescence quenching and lifetimes: role of base stacking. Proc. Natl. Acad. Sci. U. S. A. 98, $37-41$.

Jore, M.M., Lundgren, M., van Duijn, E., Bultema, J.B., Westra, E.R., Waghmare, S.P., Wiedenheft, B., Pul, U., Wurm, R., Wagner, R., et al. (2011). Structural basis for CRISPR RNA-guided DNA recognition by Cascade. Nat. Struct. Mol. Biol. 18, 529-536.

Kelch, B.A., Makino, D.L., O'Donnell, M., and Kuriyan, J. (2011). How a DNA polymerase clamp loader opens a sliding clamp. Science 334, 1675-1680.

Kidmose, R.T., Juhl, J., Nissen, P., Boesen, T., Karlsen, J.L., and Pedersen, B.P. (2019). Namdinator - automatic molecular dynamics flexible fitting of structural models into cryo-EM and crystallography experimental maps. IUCrJ 6, 526-531.

Kobayashi, M., Figaroa, F., Meeuwenoord, N., Jansen, L.E.T., and Siegal, G. (2006). Characterization of the DNA binding and structural properties of the BRCT region of human replication factor C p140 subunit. J. Biol. Chem. 281, 4308-4317.

Kobayashi, M., Ab, E., Bonvin, A.M.J.J., and Siegal, G. (2010). Structure of the DNA-bound BRCA1 C-terminal region from human replication factor C p140 and model of the protein-DNA complex. J. Biol. Chem. $285,10087-10097$.

Kremer, J.R., Mastronarde, D.N., and McIntosh, J.R. (1996). Computer visualization of three-dimensional image data using IMOD. J. Struct. Biol. $116,71-76$. 
bioRxiv preprint doi: https://doi.org/10.1101/2022.01.31.478526; this version posted January 31, 2022. The copyright holder for this preprint (which was not certified by peer review) is the author/funder, who has granted bioRxiv a license to display the preprint in perpetuity. It is made available under aCC-BY-NC-ND 4.0 International license.

Krissinel, E., and Henrick, K. (2007). Inference of Macromolecular Assemblies from Crystalline State. Journal of Molecular Biology 372, 774-797.

Kubota, T., Katou, Y., Nakato, R., Shirahige, K., and Donaldson, A.D. (2015). Replication-Coupled PCNA Unloading by the Elg1 Complex Occurs Genome-wide and Requires Okazaki Fragment Ligation. Cell Rep. 12, 774-787.

Leung, C.C.Y., and Glover, J.N.M. (2011). BRCT domains: easy as one, two, three. Cell Cycle 10, 2461-2470.

Levin, D.S., Vijayakumar, S., Liu, X., Bermudez, V.P., Hurwitz, J., and Tomkinson, A.E. (2004). A conserved interaction between the replicative clamp loader and DNA ligase in eukaryotes: implications for Okazaki fragment joining. J. Biol. Chem. 279, 55196-55201.

Liebschner, D., Afonine, P.V., Baker, M.L., Bunkóczi, G., Chen, V.B., Croll, T.I., Hintze, B., Hung, L.W., Jain, S., McCoy, A.J., et al. (2019). Macromolecular structure determination using $X$-rays, neutrons and electrons: recent developments in Phenix. Acta Crystallogr D Struct Biol 75, 861-877.

Lindahl, T., and Wood, R.D. (1999). Quality control by DNA repair. Science 286, 1897-1905.

Liu, J., Zhou, Y., and Hingorani, M.M. (2017). Linchpin DNA-binding residues serve as go/no-go controls in the replication factor $C$-catalyzed clamp-loading mechanism. J. Biol. Chem. 292, 15892-15906.

Lohman, T.M., and Fazio, N.T. (2018). How Does a Helicase Unwind DNA? Insights from RecBCD Helicase. Bioessays 40, e1800009.

Majka, J., and Burgers, P.M.J. (2004). The PCNA-RFC families of DNA clamps and clamp loaders. Prog. Nucleic Acid Res. Mol. Biol. 78, 227260.

Majka, J., Binz, S.K., Wold, M.S., and Burgers, P.M.J. (2006). Replication protein A directs loading of the DNA damage checkpoint clamp to 5'DNA junctions. J. Biol. Chem. 281, 27855-27861.

Marzahn, M.R., Hayner, J.N., Meyer, J.A., and Bloom, L.B. (2014). Kinetic analysis of PCNA clamp binding and release in the clamp loading reaction catalyzed by Saccharomyces cerevisiae replication factor C. Biochim. Biophys. Acta 1854, 31-38.

Mastronarde, D.N. (2003). SerialEM: A Program for Automated Tilt Series Acquisition on Tecnai Microscopes Using Prediction of Specimen Position. Microsc. Microanal. 9, 1182-1183.

Matsumoto, Y. (2001). Molecular mechanism of PCNA-dependent base excision repair. Prog. Nucleic Acid Res. Mol. Biol. 68, 129-138.

Matsumoto, Y., Kim, K., Hurwitz, J., Gary, R., Levin, D.S., Tomkinson, A.E., and Park, M.S. (1999). Reconstitution of proliferating cell nuclear antigen-dependent repair of apurinic/apyrimidinic sites with purified human proteins. J. Biol. Chem. 274, 33703-33708.

McNally, R., Bowman, G.D., Goedken, E.R., O'Donnell, M., and Kuriyan, J. (2010). Analysis of the role of PCNA-DNA contacts during clamp loading. BMC Struct. Biol. 10, 3.

Miyata, T., Suzuki, H., Oyama, T., Mayanagi, K., Ishino, Y., and Morikawa, K. (2005). Open clamp structure in the clamp-loading complex visualized by electron microscopic image analysis. Proc. Natl.
Acad. Sci. U. S. A. 102, 13795-13800.

Moldovan, G.-L., Pfander, B., and Jentsch, S. (2007). PCNA, the maestro of the replication fork. Cell 129, 665-679.

Naktinis, V., Turner, J., and O'Donnell, M. (1996). A molecular switch in a replication machine defined by an internal competition for protein rings. Cell 84, 137-145.

Pascucci, B., Stucki, M., Jónsson, Z.O., Dogliotti, E., and Hübscher, U. (1999). Long patch base excision repair with purified human proteins: DNA ligase I as patch size mediator for DNA polymerases $\delta$ and $\varepsilon$. J. Biol. Chem. 274, 33696-33702.

Petermann, E., Orta, M.L., Issaeva, N., Schultz, N., and Helleday, T. (2010). Hydroxyurea-stalled replication forks become progressively inactivated and require two different RAD51-mediated pathways for restart and repair. Mol. Cell 37, 492-502.

Pettersen, E.F., Goddard, T.D., Huang, C.C., Couch, G.S., Greenblatt, D.M., Meng, E.C., and Ferrin, T.E. (2004). UCSF Chimera--a visualization system for exploratory research and analysis. J. Comput. Chem. 25, 1605-1612.

Reynolds, K.A., Cameron, C.E., and Raney, K.D. (2015). Melting of Duplex DNA in the Absence of ATP by the NS3 Helicase Domain through Specific Interaction with a Single-Strand/Double-Strand Junction. Biochemistry 54, 4248-4258.

Rohou, A., and Grigorieff, N. (2015). CTFFIND4: Fast and accurate defocus estimation from electron micrographs. J. Struct. Biol. 192, 216221.

Roy, R., Kozlov, A., Lohman, T., and Ha, T. (2009). SSB protein diffusion on single-stranded DNA stimulates RecA filament formation. Nature.

Sakato, M., Zhou, Y., and Hingorani, M.M. (2012). ATP binding and hydrolysis-driven rate-determining events in the RFC-catalyzed PCNA clamp loading reaction. J. Mol. Biol. 416, 176-191.

Sattler, U., Frit, P., Salles, B., and Calsou, P. (2003). Long-patch DNA repair synthesis during base excision repair in mammalian cells. EMBO Rep. 4, 363-367.

Simonetta, K.R., Kazmirski, S.L., Goedken, E.R., Cantor, A.J., Kelch, B.A., McNally, R., Seyedin, S.N., Makino, D.L., O'Donnell, M., and Kuriyan, J. (2009). The mechanism of ATP-dependent primer-template recognition by a clamp loader complex. Cell 137, 659-671.

Sinha, R.P., and Häder, D.-P. (2002). UV-induced DNA damage and repair: a review. Photochem. Photobiol. Sci. 1, 225-236.

Subramanian, S., Gorday, K., Marcus, K., Orellana, M.R., Ren, P., Luo, X.R., O'Donnell, M.E., and Kuriyan, J. (2021). Allosteric communication in DNA polymerase clamp loaders relies on a critical hydrogen-bonded junction. Elife 10.

Szczelkun, M.D., Tikhomirova, M.S., Sinkunas, T., Gasiunas, G., Karvelis, T., Pschera, P., Siksnys, V., and Seidel, R. (2014). Direct observation of R-loop formation by single RNA-guided Cas9 and Cascade effector complexes. Proc. Natl. Acad. Sci. U. S. A. 111, 9798-9803.

Terwilliger, T.C., Ludtke, S.J., Read, R.J., Adams, P.D., and Afonine, P.V. (2020). Improvement of cryo-EM maps by density modification. Nat. Methods 17, 923-927. 
bioRxiv preprint doi: https://doi.org/10.1101/2022.01.31.478526; this version posted January 31, 2022. The copyright holder for this preprint (which was not certified by peer review) is the author/funder, who has granted bioRxiv a license to display the preprint in perpetuity. It is made available under aCC-BY-NC-ND 4.0 International license.

Trakselis, M.A., Berdis, A.J., and Benkovic, S.J. (2003). Examination of the role of the clamp-loader and ATP hydrolysis in the formation of the bacteriophage T4 polymerase holoenzyme. J. Mol. Biol. 326, 435-451.

Tsurimoto, T., and Stillman, B. (1991). Replication factors required for SV40 DNA replication in vitro. I. DNA structure-specific recognition of a primer-template junction by eukaryotic DNA polymerases and their accessory proteins. J. Biol. Chem. 266, 1950-1960.

Turner, J., Hingorani, M.M., Kelman, Z., and O'Donnell, M. (1999). The internal workings of a DNA polymerase clamp-loading machine. EMBO J. $18,771-783$.

Uhlmann, F., Gibbs, E., Cai, J., O’Donnell, M., and Hurwitz, J. (1997). Identification of regions within the four small subunits of human replication factor $\mathrm{C}$ required for complex formation and DNA replication. J. Biol. Chem. 272, 10065-10071.

Woodrick, J., Gupta, S., Camacho, S., Parvathaneni, S., Choudhury, S., Cheema, A., Bai, Y., Khatkar, P., Erkizan, H.V., Sami, F., et al. (2017). A new sub-pathway of long-patch base excision repair involving 5' gap formation. EMBO J. 36, 1605-1622.

Wyatt, M.D., and Pittman, D.L. (2006). Methylating agents and DNA repair responses: Methylated bases and sources of strand breaks. Chem. Res. Toxicol. 19, 1580-1594.

Yin, Y., Yang, L., Zheng, G., Gu, C., Yi, C., He, C., Gao, Y.Q., and Zhao, X.S. (2014). Dynamics of spontaneous flipping of a mismatched base in DNA duplex. Proc. Natl. Acad. Sci. U. S. A. 111, 8043-8048.

Yu, S.-L., and Lee, S.-K. (2017). Ultraviolet radiation: DNA damage, repair, and human disorders. Mol. Cell. Toxicol. 13, 21-28.

Zhang, K. (2016). Gctf: Real-time CTF determination and correction. J. Struct. Biol. 193, 1-12.

Zheng, F., Georgescu, R.E., Yao, N.Y., O’Donnell, M.E., and Li, H. (2021). Rad24-RFC loads the 9-1-1 clamp by inserting DNA from the top of a wide-open ring, opposite the mechanism of RFC/PCNA.

Zivanov, J., Nakane, T., Forsberg, B.O., Kimanius, D., Hagen, W.J., Lindahl, E., and Scheres, S.H.W. (2018). New tools for automated highresolution cryo-EM structure determination in RELION-3. Elife 7. 